\title{
Association between social group participation and perceived health among elderly inhabitants of a previously methylmercury- polluted area
}

\author{
Mika Tanaka $\cdot$ Kayo Ushijima $\cdot$ Woncheol Sung • \\ Minoru Kawakita $\cdot$ Shiro Tanaka $\cdot$ Yoshito Mukai \\ Kenji Tamura $\cdot$ Sadami Maruyama
}

Received: 22 July 2013 / Accepted: 24 February 2014/Published online: 19 March 2014

(C) The Japanese Society for Hygiene 2014

\begin{abstract}
Objective This study attempted to clarify the association between participation in a social group and perceived health among elderly residents of a previously methylmercury-polluted area in Japan.

Methods We conducted a cross-sectional study using eligible subjects from the Shiranui Sea coastal area, where mercury poisoning due to daily intake of fish and shellfish had previously caused some residents to develop the
\end{abstract}

M. Tanaka $(\bowtie)$

School of Health Science, Tokai University, 143 Shimokasuya, Isehara-shi, Kanagawa 259-1193, Japan

e-mail: mktanaka@tokai-u.jp

K. Ushijima

Department of Preventive Medicine and Public Health, Faculty

of Medicine, Fukuoka University, Fukuoka, Japan

W. Sung

School of Sociology, Chukyo University, Nagoya, Japan

M. Kawakita

Graduate School of Practitioners in Education, Aichi University of Education, Kariya, Japan

S. Tanaka

Translational Research Center, Kyoto University, Kyoto, Japan

Y. Mukai

Faculty of Health Science, Kumamoto Health Science

University, Kumamoto, Japan

K. Tamura

Environmental Health Science Division, National Institute

for Environmental Studies, Tsukuba, Japan

S. Maruyama

Kumamoto University, Kumamoto, Japan neurological disorder "Minamata disease (MD)." In the present study, we selected subjects aged $\geq 65$ years who had never been diagnosed with MD or applied for medical treatment compensation.

Results A logistic regression model after adjusting for confounding factors showed that membership in a hobby or volunteer group was associated with good perceived health (odds ratio 1.97, $95 \%$ confidence interval 1.02-3.80).

Conclusion Our results showed that the effects of membership in social groups on perceived health were not equal across all social groups, with only hobby- or volunteerrelated groups having a positive effect on perceived health. Our findings suggested that promoting participation in a social group such as hobby- or volunteer-related groups can help improve perceived health among elderly individuals who had experienced environmental pollution incidents.

Keywords Perceived health - Community networks . Aged $\cdot$ Methylmercury-polluted area

\section{Introduction}

The subjective indicator of "perceived health" is an integrated indicator for health evaluation and can be used to predict morbidity, loss of functional capacity, and mortality independently of objective health conditions among the elderly [1-5].

Poor perceived health has been reported to persist for prolonged duration among residents of areas polluted by poisonous chemicals or radiation [6-11], suggesting that perceived health was poor not only among those residents granted medical compensation for evidenced health injury due to exposure to a large amount of pollutant but also in those not granted compensation for reasons of not 
presenting definite symptoms associated with the pollutant and being thereby judged not to have been subjected to non-negligible exposure.

In the 1950s, the area around the Shiranui Sea in Japan suffered from severe methylmercury contamination due to factory wastewater, and residents with high intake of fish and shellfish from the sea developed methylmercury poisoning, known as Minamata disease (MD). Since the disease was first identified in 1956, a prefectural government committee has confirmed approximately 2,200 inhabitants of the polluted sea area as MD patients and cited them as eligible for compensation. However, the standard of certification was extremely narrow, initially focusing only on acute cases, and in 1995, the Japanese government determined that approximately 10,000 residents who had previously not been certified as having MD but in whom the debilitating effects of methylmercury could not be ruled out were eligible for additional medical compensation (lump sum, all medical expenses and other allowance). These measures came about subsequently due to difficulties in definitively diagnosing a patient with MD, as neurological diseases such as MD are diagnosed largely based on subjective symptoms. While approximately 60 years have now passed since the poisoning, confusion regarding health issues and compensation persists in the Shiranui Sea area as residents reach advanced age.

Recent studies have reported that perceived health as compared with residents of non-polluted areas is poor even among residents of the affected area not diagnosed with MD or compensated $[12,13]$. It has also been reported that many residents of the affected area cannot eliminate worries about their symptoms (even though not typical MD symptoms) that might be related to exposure to methylmercury.

While priority should naturally be placed on relieving symptoms of methylmercury poisoning among residents diagnosed with MD or those compensated with medical care, we should take care not to neglect those residents not diagnosed with MD or compensated but who still report poor perceived health, as poor perceived health is expected to reduce activity in daily living and increase morbidity and hospital use in the near future among the elderly [3-5].

In an effort to improve overall perceived health, a number of studies have investigated factors relating to perceived health among general populations of elderly individuals. These previous studies reported socio-economic status, lifestyle factors, social support, and social network including family, friends, and social group membership as factors associated with perceived health [14-16]. Of these factors, social group membership was identified as a particularly important determinant of health for the elderly, intervention in which is an effective method of promoting health lifestyles among the elderly [17, 18].
However, no study has yet evaluated the association between perceived health and social group membership among elderly inhabitants of a previously toxic substancepolluted area.

The impact of the radioactive diffusion due to the accident at the Fukushima nuclear power plant in Japan in March 2011 is immeasurable. Unlike with acute radiation, assessment of extent of late radiation injuries such as cancer and influence on fetus development after a prolonged period is difficult. As such, confusion related to health issues and compensation merit have undoubtedly persisted for some time among residents of afflicted areas, and a considerable number of these residents are predicted to have poor perceived health regardless of whether they have been deemed subject to compensation or not. Given this immediate need, methods for improving perceived health of these residents should be explored as soon as possible.

Here, we clarified the association between perceived health and social group membership and determined which type of social group provides significant benefit to perceived health among the elderly in an area previously polluted with methylmercury in Japan.

\section{Materials and methods}

\section{Study population}

We used data from a survey of residents living in communities bordering the Shiranui Sea (Shiranui Study). Details on sampling methods in the Shiranui Study have been described elsewhere [13]. Briefly, of the approximately 59,000 residents aged 40-79 years of 172 postal code areas across 6 local government regions in the Shiranui Sea area, 105 (1 person per household) per postal code area were randomly sampled. Questionnaires were mailed to the eligible subjects and collected 1-2 weeks later during a home visit. If the eligible subjects were absent when called upon or had not completed the questionnaire even after repeated visits, they were asked to return the completed questionnaire by mail using a stamped, self-addressed envelope. After application of exclusion criteria, 2,100 eligible subjects remained, 1,548 of which agreed to participate (response rate $73.7 \%$ ). Of these, surveys from 1,297 were collected by home visit and 251 by mail. All subjects gave informed consent in written form for participation in the study.

For the present study, we selected only those subjects aged $\geq 65$ years who had never been diagnosed with MD or received medical treatment compensation, as most had serious MD symptoms which greatly affected their perceived health and thus limited their participation in social 
groups, thereby directly hampering investigation of the relationship between perceived health and participation in social groups.

The study design was approved by the Ethics Committee of Fukuoka University.

\section{Measurement}

The questionnaire distributed to residents consisted of questions on perceived health, social group membership, socio-demographic characteristics, and health status. Perceived health was assessed by asking, "all in all, would you say your health is generally excellent, good, fair, or poor?" [19]. This simple concept was found to be associated with morbidity, loss of functional capacity, and mortality among the elderly, suggesting it to be a good comprehensive marker for health of aged individuals [3-5].

Four social groups were defined based on voluntariness and horizontal relationships considering the aim of forming the relationship: community-related groups such as neighborhood associations or women's associations; businessrelated groups such as consumer organizations or industrial associations; hobby- or volunteer-related groups such as further-education institutions, sports and cultural clubs, and voluntary societies; and belief-related groups such as religious or political organizations. Group memberships were evaluated considering the frequency of participation. We assign the score for each group ( 0 never or seldom, 1 often or always).

Sex (0 female, 1 male), age (65-69, 70-74, and 75+ years), living arrangement (living alone, with a spouse only, with a spouse and family members, and living with family members other than spouse), education (less than high school, high school, more than high school), income (annual income per capita divided into quarters), activity of daily living (ADL), and existence of chronic disease under treatment including physical and mental disease (0 no, 1 yes) were considered either or both potential confounders or modifiers of the association between perceived health and social group membership in the elderly. ADL was evaluated regarding bathing or showering, dressing/ undressing, going to the toilet, walking, eating, shaving/ brushing, putting on make-up, making a phone call, traveling by bus or train, daily shopping, cooking, cleaning a room, taking medicine, and managing finances [20, 21]. We assigned a score for each item ( 0 unable to be completed, 1 difficult to be completed, 2 easily able to be completed) and used the summed values as ADL scores.

\section{Statistical analysis}

In our analysis of subset data of the Shiranui Study, we first excluded records with missing values on perceived health and group memberships and then selected subjects aged $\geq 65$ years who had not been diagnosed with MD or received medical treatment compensation.

A logistic regression model with a generalized estimating equation (GEE) for responses with missing data on potential confounding factors was used to estimate the association between perceived health and social group membership. For dependent variables, we assigned a dichotomous variable for perceived health ( 0 fair or poor; 1 good or excellent). Odds ratios (OR) and $95 \%$ confidence intervals (CIs) with and without adjustment for potential confounding factors were reported as results. All analyses were performed using SPSS for Windows ver. 17.0 J (SPSS Inc., Chicago, IL, USA). All tests were two-tailed, with significance set at 0.05 .

\section{Results}

Of the 1,548 subjects in the Shiranui Study, 626 were $\geq 65$ years of age. Of those 626,5 had been diagnosed with $\mathrm{MD}$, and 213 had received medical treatment compensation without being diagnosed with MD. Therefore, we included a total of 408 subjects aged $\geq 65$ years who had neither been diagnosed with MD nor received medical treatment compensation in the analysis.

Characteristics of study subjects are presented in Table 1. A total of $28.7 \%$ (117/408) of subjects rated their health status as poor $(35,8.6 \%)$ or fair $(82,20.1 \%)$, and that of $71.3 \%(291 / 408)$ as $\operatorname{good}(253,62.0 \%)$ and excellent $(38,9.3 \%)$. Forty-eight percent of participants had less than a high school education, and $14 \%$ lived alone while $45 \%$ lived with spouse only. Sixty-one percent had a chronic disease requiring medical treatment. Regarding community-related group participation, $34.6 \%(141 / 408)$ of subjects always participated, $14.0 \%$ (57/408) often participated, $13.2 \%$ (54/408) seldom participated, and $38.2 \%$ (156/408) never participated. Regarding businessrelated group participation, $11.8 \%$ (48/408) of subjects always participated, $6.1 \%(25 / 408)$ often participated, $27.0 \%$ (110/408) seldom participated, and $55.1 \%$ (225/ 408) never participated. Regarding hobby- and volunteerrelated groups, $23.0 \%(94 / 408)$ of subjects always participated, $7.9 \%$ (32/408) often participated, $22.8 \%$ (93/ 408) seldom participated, and $46.3 \%(189 / 408)$ never participated. Regarding belief-related groups, $22.1 \%$ (90/ 408) of subjects always participated, $7.1 \%$ (29/408) often participated, $2.9 \%$ (12/408) seldom participated, and $67.9 \%(277 / 408)$ never participated.

In a univariate analysis, respondents in the hobby- or volunteer-related groups reported a significantly higher ratio of good or excellent perceived health of the four social group types. Among potential confounders, ratios of 
Table 1 Distribution of demographic and socioeconomic characteristics of the study population

All data are presented as number $(\%)$ or mean (SD)

Number for respective group may not sum to total due to missing values

a Categorical variables were analyzed by Fisher's exact tests, and continuous variables were analyzed by $t$ tests

${ }^{b}$ Multiple answer

\begin{tabular}{|c|c|c|c|c|}
\hline & $\begin{array}{l}\text { Total } \\
N=408\end{array}$ & $\begin{array}{l}\text { Fair or poor } \\
\text { health } \\
N=117\end{array}$ & $\begin{array}{l}\text { Good or } \\
\text { excellent } \\
N=291\end{array}$ & $p^{\mathrm{a}}$ \\
\hline \multicolumn{5}{|l|}{ Age, years, $n(\%)$} \\
\hline $65-69$ & $146(35.8)$ & $42(35.9)$ & $104(35.7)$ & \multirow[t]{3}{*}{0.57} \\
\hline $70-74$ & $153(37.5)$ & $40(34.2)$ & $113(38.8)$ & \\
\hline 75 and above & 109 (26.7) & $35(29.9)$ & $74(25.5)$ & \\
\hline \multicolumn{5}{|l|}{ Sex, $n(\%)$} \\
\hline Male & $193(47.3)$ & $55(47.0)$ & $138(47.4)$ & \multirow[t]{2}{*}{0.94} \\
\hline Female & $215(52.7)$ & $62(53.0)$ & $153(52.6)$ & \\
\hline \multicolumn{5}{|l|}{ Living arrangement, $n(\%)$} \\
\hline Living alone & $56(14.1)$ & $22(19.2)$ & $34(12.1)$ & \multirow[t]{3}{*}{0.15} \\
\hline Living with a spouse only & $179(45.2)$ & $46(40.4)$ & $133(47.2)$ & \\
\hline $\begin{array}{l}\text { Living with a spouse and family } \\
\text { members }\end{array}$ & $161(40.7)$ & $46(40.4)$ & $115(40.7)$ & \\
\hline \multicolumn{5}{|l|}{ Educational level, $n(\%)$} \\
\hline Less than high school & $187(47.7)$ & $48(42.9)$ & 139 (49.6) & \multirow[t]{3}{*}{0.33} \\
\hline High school & $164(41.8)$ & $49(43.8)$ & $115(41.1)$ & \\
\hline More than high school & $41(10.5)$ & $15(13.3)$ & $26(9.3)$ & \\
\hline \multicolumn{5}{|l|}{ Annual income per capita, yes, $n(\%)$} \\
\hline$<750,000$ & $74(19.8)$ & $22(21.2)$ & $52(19.3)$ & \multirow[t]{4}{*}{0.90} \\
\hline $750,000-910,000$ & $113(30.3)$ & $32(30.8)$ & $81(30.1)$ & \\
\hline $920,000-1,490,000$ & $70(18.8)$ & $17(16.3)$ & $53(19.7)$ & \\
\hline$>1,500,000$ & $116(31.1)$ & $33(31.7)$ & $83(30.9)$ & \\
\hline Chronic disease, yes, $n(\%)$ & $243(61.4)$ & $90(37.0)$ & $153(63.0)$ & $<0.001$ \\
\hline ADL scores, mean (SD) & $14.4(3.4)$ & $15.9(5.1)$ & $13.7(2.2)$ & $<0.001$ \\
\hline \multicolumn{5}{|c|}{ Group memberships ${ }^{\mathrm{b}}$, often and always, $n(\%)$} \\
\hline Community related group & $198(48.5)$ & $48(24.2)$ & $150(75.8)$ & 0.06 \\
\hline Business-related group & $73(17.9)$ & $19(26.0)$ & $54(74.0)$ & 0.67 \\
\hline Hobby- and volunteer-related group & $126(30.9)$ & $24(19.0)$ & $102(81.0)$ & $<0.01$ \\
\hline Belief-related group & $119(29.2)$ & $28(23.5)$ & $91(76.5)$ & 0.15 \\
\hline
\end{tabular}

subjects without chronic disease and mean ADL scores were higher in those who reported good or excellent perceived health.

Results of multiple logistic regression analysis for associations between perceived health and social group membership are presented in Table 2 . In our unadjusted model, membership in hobby- or volunteer-related groups was associated with good or excellent perceived health (OR 1.87, $95 \%$ CI 1.07-3.27), and even after adjusting for all variables, memberships in these groups remained associated with perceived health (OR 1.97, $95 \%$ CI 1.02-3.80).

\section{Discussion}

We examined the association between perceived health and social group membership among elderly residents of a previously methylmercury-polluted area in Japan. Our findings demonstrated the significant relationship between perceived health of residents and membership in a hobbyor volunteer-related group.

Although the immediate and short-term impact of largescale disasters on health or psychosocial aspects has been studied [22-24], factors related to the health of residents caught up in the long-term confusion following a disaster have not been fully examined. Further, few studies have investigated the relationship between health and social group membership, which is believed an important determinant of health among residents. Beehler et al. [6] conducted a cross-sectional study to investigate factors influencing long-term mental health outcomes of 381 residents almost 20 years after the Chernobyl nuclear power plant disaster. The results of hierarchical linear modeling showed that long-term distress levels were predicted by stress-moderating psychosocial factors such as perceived family problems, not by the level of residential radiation contamination. 
Table 2 Association between perceived health and social group membership
$*<0.05, * *<0.01$

${ }^{\text {a }}$ Unadjusted odds ratio

b Adjusted for the variables of physician contact by chronic disease and ADL scores

c Adjusted for the variables of age, sex, living arrangement, education level, annual income per capita, physician contact by chronic disease, and ADL scores

\begin{tabular}{|c|c|c|c|}
\hline & \multicolumn{3}{|c|}{ Odds ratio $(95 \% \mathrm{CI})$} \\
\hline & Model $1^{\mathrm{a}}$ & Model $2^{\mathrm{b}}$ & Model $3^{\mathrm{c}}$ \\
\hline \multicolumn{4}{|l|}{ Group memberships } \\
\hline Community-related group & $1.24(0.77-2.00)$ & $1.14(0.68-1.91)$ & $1.00(0.56-1.79)$ \\
\hline Business-related group & $0.86(0.46-1.61)$ & $0.92(0.47-1.79)$ & $0.99(0.47-2.10)$ \\
\hline Hobby- and volunteer-related group & $1.87(1.07-3.27)^{*}$ & $1.82(1.01-3.26)^{*}$ & $1.97(1.02-3.80)^{*}$ \\
\hline Belief-related group & $1.22(0.71-2.08)$ & $1.05(0.59-1.86)$ & $1.30(0.68-2.48)$ \\
\hline \multicolumn{4}{|l|}{ Age } \\
\hline $65-69$ & & & 1 \\
\hline $70-74$ & & & $1.47(0.80-2.72)$ \\
\hline 75 and above & & & $1.91(0.97-3.77)$ \\
\hline \multicolumn{4}{|l|}{ Sex } \\
\hline Male & & & 1 \\
\hline Female & & & $0.91(0.52-1.61)$ \\
\hline \multicolumn{4}{|l|}{ Living arrangement } \\
\hline Living alone & & & 1 \\
\hline Living with a spouse only & & & $3.74(1.38-10.14)^{*}$ \\
\hline $\begin{array}{l}\text { Living with a spouse and family } \\
\text { members }\end{array}$ & & & $4.31(1.40-13.24)^{*}$ \\
\hline \multicolumn{4}{|l|}{ Educational level } \\
\hline Less than high school & & & 1 \\
\hline High school & & & $0.53(0.30-0.96)^{*}$ \\
\hline More than high school & & & $0.27(0.11-0.66)^{* *}$ \\
\hline \multicolumn{4}{|l|}{ Annual income per capita } \\
\hline$<750,000$ & & & 1 \\
\hline $750,000-910,000$ & & & $1.55(0.61-3.96)$ \\
\hline $920,000-1,490,000$ & & & $1.91(0.67-5.49)$ \\
\hline$>1,500,000$ & & & $3.00(0.97-9.34)$ \\
\hline Chronic disease & & $0.37(0.22-0.62)^{* *}$ & $0.28(0.15-0.52)^{* *}$ \\
\hline ADL scores & & $0.84(0.77-0.92)^{* *}$ & $0.82(0.74-0.91)^{* *}$ \\
\hline
\end{tabular}

The positive impact of participation in a hobby- or volunteer-related group demonstrated in the present study is consistent with findings of previous studies among the elderly [25-27]. A population-based survey to assess perceived health among non-disabled elderly individuals living alone and the factors associated with good perceived health found that participation in social groups such as recreational activities and hobby associations was a positive factor in females, although contact with relatives, friends, or confidants was not significant in either gender [26]. Similarly, another community survey revealed that the association between associational involvement, including sports club and hobby, or volunteer activity and perceived health among the elderly [18]. A six-year longitudinal study was carried out to investigate the predictors of perceived health by Giordano et al. [17]. The result showed that social participation in local groups, voluntary organization or group leisure activities were independent predictors of good perceived health, even after adjusting for other well-known health determinants. They suggested that the participations in such groups should lead less anxiety and that less anxious individuals may be less susceptible to the negative health outcomes. Anxiety can, via the hypothalamic-pituitary-adrenal axis, lead to increased level of blood cortisol [28], and elevated cortisol level has been linked to negative health outcomes such as metabolic syndrome, depression and so on [29].

Putnam suggested that voluntary organizations are particularly rich environments for people to learn civic skills through working together and lead to elevated health status, including perceived health [30, 31]. In general, levels of volunteerism are high in hobby- and volunteer-related networks, as these groups are predominantly homogeneous, with individuals relatively similar to one other with regard to interests and values. Further, network ties in these social groups seem to be primarily reciprocal relationships and horizontal social interactions, involving more positive connections than other group types. 
While the relationship between participation in a hobbyor volunteer-related group and perceived health was found to be significant, no significance was detected in the relationships of other group memberships-such as community-related groups, business-related groups, or beliefrelated groups-and perceived health among the elderly residents of the area. Sun et al. [26] conducted a large-scale population-based survey investigating the association between self-rated health (SRH) and social activities among the elderly in Japan. In univariate analysis, SRH was significantly correlated with social networks assessed according to variables such as frequency of contact with friends and confidants. However, in multivariate analysis, after adjusting for social integration assessed according to whether respondents participated or not in recreational activities or hobby associations, the relationship between SRH and social networks lost significance, indicating that the relationship between SRH and social integration itself is significant. These authors' findings that participation in recreational activities or hobby associations had a stronger effect on SRH than social networks supported our findings in the present study. With regard to the community-related groups, the sample size could be small. For the distribution of this group (48/117 vs. 150/291), the statistic power for a logistic regression model with sample size of 408 ( $\alpha=0.05$, two-tailed) was 0.45 .

The reason for the lack of any observed relationship between perceived health and business-related groups is unclear. Only 73 subjects participated in business-related groups, and most of these elderly subjects in the area could be farmers or fishermen working alone or with a family, although they belonged to an agricultural association or fisheries cooperative association. The frequency of participation in groups related to farms or fisheries is generally lower than frequencies of participation in other business-related groups.

Belief-related groups were also found to have a nonsignificant relationship with perceived health among the elderly in the affected area, possibly because religious participation is valued relatively lowly in Japan compared with Western countries, where participation in religious events is highly valued [32-34]. Although few studies have examined the relationship between health and religion, a previous report investigating ethnic differences in religiosity and mental health showed that effects of religiosity on mental health were lowest among Asians, compared with Hispanics, Africans, and Caucasians [35].

Several limitations to the present study warrant mention. First, the cross-sectional nature of our study limited to infer causal relationship between perceived health of the elderly residents and membership in a hobby- or volunteer-related group. Second, to rule out the possible influence of methylmercury poisoning on perceived health and participation in social groups, subjects in this study were limited to those who had not been diagnosed with MD or granted medical compensation. The sample size of 408 was, therefore, insufficient to achieve statistic power. The association between social relationships and perceived health observed in the present study may have been largely due to a selection effect, as health problems can hinder people from forming social relationships. However, we do point out that the observed association remained even after controlling for ADL and the presence of chronic disease, and further analysis performed after eliminating participants with a low ADL score had no effect on findings (results not shown). Third, although accessibility is a strong factor influencing participation in social groups, we did not investigate it in the present study. In addition, potential confounding variables such as mental status or physical condition were not circumstantially investigated due to survey limitations. Fourth, we did not inquire as to whether a resident in the polluted area was a member or not of a class-action lawsuit seeking medical compensation, despite the fact that their perceived health was likely influenced by this factor.

However, despite the above-described limitations, our present findings suggesting the importance of participating in hobby- or volunteer-related groups to maintain good perceived health among elderly residents of a methylmercury-polluted area remain important. Serious pollution incidents always injure local residents as well as leave behind lingering secondary psychosocial effects associated with environmental pollution, such as anxiety concerning complete elimination of pollution, long-term effects of pollution, and prolonged compensation-related confusion. Such conditions are likely to be taken for granted in the confusion following a pollution incident.

Our present findings demonstrated a relationship between perceived health of residents and membership in a hobby- or volunteer-related group mainly via volunteerism and horizontal interaction, even in populations caught up in the confusion following an environmental incident. Our findings further suggest the significance of and need for an interventional study confirming that promotion of group membership in polluted areas can improve perceived health of residents.

Acknowledgments We sincerely thank the participants in this survey, the staff of Kumamoto and Kagoshima Prefectures for providing data of Minamata disease patients per postal code area, and the research assistants for conducting the field survey. We are particularly grateful to Ms. Fukumoto and the staff of the Shiranui Study Group for support provided during data collection.

\section{References}

1. Appels A, Bosma H, Grabauskas V, Gostautas A, Sturmans F. Self-rated health and mortality in a Lithuanian and a Dutch population. Soc Sci Med. 1996;42:681-9. 
2. Idler EL, Kasl S. Health perceptions and survival: do global evaluations of health status really predict mortality? J Gerontol. 1991;46:55-65.

3. Mossey JM, Shapiro E. Self-rated health: a predictor of mortality among the elderly. Am J Public Health. 1982;72:800-8.

4. Idler EL, Kasl SV. Self-ratings of health: do they also predict change in functional ability? J Gerontol B Psychol Sci Soc Sci. 1995;50:344-53.

5. Mor V, Wilcox V, Rakowski W, Hiris J. Functional transitions among the elderly: patterns, predictors, and related hospital use. Am J Public Health. 1994;84:1274-80.

6. Beehler GP, Baker JA, Falkner K, Chegerova T, Pryshchepava A, Chegerov V, et al. A multilevel analysis of long-term psychological distress among Belarusians affected by the Chernobyl disaster. Public Health. 2008;122:1239-49.

7. Matthies E, Hoger R, Guski R. Living on polluted soil: determinants of stress symptoms. Environ Behav. 2000;32:270-86.

8. Peek MK, Cutchin MP, Freeman D, Stowe RP, Goodwin JS. Environmental hazards and stress: evidence from the Texas City Stress and Health Study. J Epidemiol Community Health. 2009;63:792-8.

9. Vandermoere F. Psychosocial health of residents exposed to soil pollution in a Flemish neighbourhood. Soc Sci Med. 2008;66:1646-57.

10. Powell M, Dunwoody S, Griffin R, Neuwirth K. Exploring lay uncertainty about an environmental health risk. Public Underst Sci. 2007;16:323-43.

11. Lima ML. On the influence of risk perception on mental health: living near an incinerator. J Environ Psychol. 2004;24:71-84.

12. Ushijima K, Miyake Y, Kitano T, Shono M, Futatsuka M. Relationship between health status and psychological distress among the inhabitants in a methylmercury-polluted area in Japan. Arch Environ Health. 2004;59:725-31.

13. Ushijima K, Sung W, Kawakita M, Mukai Y, Tamura K, Tanaka $\mathrm{S}$, et al. Association between Minamata disease status and activities of daily living among inhabitants in previously methylmercury-polluted areas. Nihon Eiseigaku Zasshi. 2008;63:699-710.

14. Cheng ST, Chan AC. Social support and self-rated health revisited: is there a gender difference in later life? Soc Sci Med. 2006;63:118-22.

15. Zunzunegui MV, Beland F, Otero A. Support from children, living arrangements, self-rated health and depressive symptoms of older people in Spain. Int J Epidemiol. 2001;30:1090-9.

16. Wang N, Iwasaki M, Otani T, Hayashi R, Miyazaki H, Xiao L, et al. Perceived health as related to income, socio-economic status, lifestyle, and social support factors in a middle-aged Japanese. J Epidemiol. 2005;15:155-62.

17. Giordano GN, Lindstrom M. The impact of changes in different aspects of social capital and material conditions on self-rated health over time: a longitudinal cohort study. Soc Sci Med. 2010;70:700-10.

18. Schultz J, O'Brien AM, Tadesse B. Social capital and self-rated health: results from the US 2006 social capital survey of one community. Soc Sci Med. 2008;67:606-17.

19. Hennessy CH, Moriarty DG, Zack MM, Scherr PA, Brackbill R. Measuring health-related quality of life for public health surveillance. Public Health Rep. 1994;109:665-72.
20. George LK, Fillenbaum GG. OARS methodology. A decade of experience in geriatric assessment. $\mathrm{J}$ Am Geriatr Soc. 1985;33:607-15.

21. Katz S, Ford AB, Moskowitz RW, Jackson BA, Jaffe MW. Studies of illness in the aged. The Index of ADL: a standardized measure of biological and psychosocial function. JAMA. 1963; $185: 914-\overline{9}$.

22. Jordan HT, Stellman SD, Morabia A, Miller-Archie SA, Alper H, Laskaris Z, et al. Cardiovascular disease hospitalizations in relation to exposure to the September 11, 2001 World Trade Center disaster and posttraumatic stress disorder. J Am Heart Assoc. 2013;2:e00431.

23. Isaranuwatchai W, Coyte PC, McKenzie K, Noh S. Impact of the 2004 tsunami on self-reported physical health in Thailand for the subsequent 2 years. Am J Public Health. 2013;103:2063-70.

24. Cwikel J. Comments on the psychosocial aspects of the International Conference on Radiation and Health. Environ Health Perspect. 1997;105:1607-8.

25. Lindstrom M, Moghaddassi M, Merlo J. Individual self-reported health, social participation and neighbourhood: a multilevel analysis in Malmo, Sweden. Prev Med. 2004;39:135-41.

26. Sun W, Watanabe M, Tanimoto Y, Shibutani T, Kono R, Saito M, et al. Factors associated with good self-rated health of non-disabled elderly living alone in Japan: a cross-sectional study. BMC Public Health. 2007;7:297.

27. Zunzunegui MV, Kone A, Johri M, Beland F, Wolfson C, Bergman H. Social networks and self-rated health in two Frenchspeaking Canadian community dwelling populations over 65 . Soc Sci Med. 2004;58:2069-81.

28. Shively CA, Musselman DL, Willard SL. Stress, depression, and coronary artery disease: modeling comorbidity in female primates. Neurosci Biobehav Rev. 2009;33:133-44.

29. Vogelzangs N, Beekman AT, Dik MG, Bremmer MA, Comijs $\mathrm{HC}$, Hoogendijk WJ, et al. Late-life depression, cortisol, and the metabolic syndrome. Am J Geriatr Psychiatry. 2009;17:716-21.

30. Putnam R. The strange disappearance of civic America. Am Prospec. 1996;24:34-48.

31. Putnam R. Bowling alone: the collapse and revital of American community. New York: Simon and Schuster; 2000.

32. Hodge DR, Horvath VE. Spiritual needs in health care settings: a qualitative meta-synthesis of clients' perspectives. Soc Work. 2011;56:306-16.

33. Shojaei P, Karimloo M, Mohammadi F, Malek Afzali H, Forouzan AS, et al. Position of social determinants of health in urban man-made lakes plans. Glob J Health Sci. 2013;5:100-11.

34. Webb JR, Hirsch JK, Visser PL, Brewer KG. Forgiveness and health: assessing the mediating effect of health behavior, social support, and interpersonal functioning. J Psychol. 2013;147: 391-414.

35. Robinson JA, Bolton JM, Rasic D, Sareen J. Exploring the relationship between religious service attendance, mental disorders, and suicidality among different ethnic groups: results from a nationally representative survey. Depress Anxiety. 2012;29: 983-90. 